\title{
Psychoeducation Effectiveness on Expectations About Counseling for a Mental IIIness Among the Youth: A Case Study of Teacher-Trainees in Kenya
}

\author{
Eunice Jemalel Nyavanga ${ }^{1,2, *}$, Ivy Mmbone Chebet $^{3}$, Mourice Barasa Wafula ${ }^{4}$, \\ David Musyimi Ndetei ${ }^{5}$ \\ ${ }^{1}$ Department of Social and Human Development, Faculty of Social Sciences and Technology, the Technical University of Kenya, Nairobi, \\ Kenya \\ ${ }^{2}$ Malel Bibwob Clinical Psychologists Consultancy (MICAP), Nairobi, Kenya \\ ${ }^{3}$ St. Vincent Private Hospital, Department of Nursing (Neuroscience), Melbourne, Australia \\ ${ }^{4}$ M\&E, International Planned Parenthood Federation, Africa Region, Nairobi, Kenya \\ ${ }^{5}$ Department of Psychiatry, Faculty of Health Sciences, University of Nairobi, Nairobi, Kenya
}

\section{Email address:}

enyavanga@yahoo.com (E. J. Nyavanga), ivymmbone@yahoo.com (I. M. Chebet) barazam@gmail.com (M. B. Wafula), dmndetie@amhf.or.ke (D. M. Ndetei)

${ }^{*}$ Corresponding author

\section{To cite this article:}

Eunice Jemalel Nyavanga, Ivy Mmbone Chebet, Mourice Barasa Wafula, David Musyimi Ndetei. Psychoeducation Effectiveness on Expectations About Counseling for a Mental Illness Among the Youth: A Case Study of Teacher-Trainees in Kenya. American Journal of Applied Psychology. Vol. 6, No. 4, 2017, pp. 57-63. doi: 10.11648/j.ajap.20170604.12

Received: June 10, 2017; Accepted: June 20, 2017; Published: September 21, 2017

\begin{abstract}
Expectations are subjectively held statements that represent an individual's estimate of likelihood that an event will occur. Several researches has explored on expectations about counseling in various populations globally related to a number of situations. This study aims to determine effectiveness of psychoducation on expectations about counseling for a mental illness among the youth in Kenya. Sampling of four colleges out of the existing twenty public teacher-training colleges was done. Participants were divided into two groups, experimental and control groups and presented with self-administered questionnaires at baseline. Psychoeducation was done to the experimental group and second assessment was done, the third assessment was done three months after the psychoeducation and a fourth assessment was done six months after the psychoeducation using same instruments. The control group was assessed three times, baseline, three months after and six months after. Ethics Committee followed ethical protocol from approval to informed consent from the participants. This study found out that psychoeducation improved expectations about counseling for at least six months and recommended that mental illness and expectations about counseling should be included in the teacher trainee curriculum.
\end{abstract}

Keywords: Expectation, Counseling, Psychoeducation, Teacher Trainees, Effectiveness

\section{Introduction}

Expectations are subjectively held probability statements that represent an individual's estimate of likelihood that an event will occur. They refer to the future and exist in the absence of an earlier experience with an event or condition. Tinsley, et al [1] has defined expectations as "a persons understanding of the probability that an event will occur".

Several studies have explored on expectations about counseling among various populations globally related to depression, hopelessness and self-discrepancies, [2], cultural influences, [3]; counselor ethnicity, [4]; common stressors, [5], Personality, [6] gender and help seeking, and knowledge about services, [7].

Nyavanga \& Barasa, [8], explored the expectations about counseling among primary school teacher trainees in Kenya; they found out that these expectations were negative and they recommended on interventions to improve expectations of 
counseling on a mental illness.

\subsection{Role of Expectations About Counseling for a Mental Illness}

Client expectations about counseling are known to influence the counseling process and its outcomes. It influences the client's decision to enter into and remain in counseling while moderating the efficacy of counseling. Expectations contribute to the treatment and outcome syndrome development among individuals with anxiety disorders, [9].

\subsection{Counseling in Kenya}

Professional counseling in Kenya is still very new, with few licensing bodies that give certification and is seen as a western concept. In the last twenty years, Kenya has embraced professional counseling due to the emergence of terrorism, HIV/AIDS epidemic, student unrest in schools and universities, the political and social unrest and the rise of alcohol and drug use among the youth.

\subsection{Justifications and Significance of the Study}

Prevalence of mental disorders have been found to be at $37.7 \%$ with those having more than one disorder being at $18.2 \%$ among primary school going children in Kenya [10]. In addition these individuals face high stigma levels, [11]. Further more these conditions are complicated with high prevalence of alcohol and other drug use, [12] that has led to the rise of HIV/AIDS epidemic.

This study is aimed at determining the efficacy of psychoeducation in improving expectations about counseling for a mental health problem among the youth. The results should be able to inform policy makers in the country to improve counseling for mental health problems among the young people, in order to reduce the effects of traumatic events the youth go through in Kenya, due to HIV/AIDS, alcohol and drug use, and political and social unrest.

\section{Methodology and Study Design}

\subsection{Methods}

\subsubsection{Settings and Study Population}

The estimated participants were 3,400 out of about 17 , 000 trainees. We were informed that public teacher colleges recruited trainees on a quota system, so the participants came from all over the country. Participants were 2925 young people training in public primary teachers colleges conveniently recruited from four out of the existing twenty colleges; of whom 1466 (52.8\%) were female, majority $59.9 \%$ were between the ages $21-25$ years, $77.7 \%$ were not married and $96.0 \%$ were Christians.

Two colleges out of the four identified colleges made the control group while the other two formed the experimental group. All the trainees present at the college at the time of the study who consented to take part in the study were recruited.

\subsubsection{Ethical Considerations}

The Kenyatta National Hospital and University of Nairobi Ethics (KNH-UN-EC), that sets research ethics for research that uses individual data in Kenya approved the research protocol. Permission to collect data, was provided by the Ministry of Education, Research Department. This approval and permission were presented to the College principals with a clear explanation on the purpose, plan and implication of the study. The participants were informed that participation was voluntary that had no intrusive procedures, but if they experienced any emotional feelings, they could see the college counselors or the researchers and research assistants whose contacts were provided.

\subsubsection{Study Procedures and Instrumentation}

The participants were met in their normal classroom settings and the demographic questionnaire and the Expectations about Counseling were presented to them as they sat on their normal desks. They answered the questionnaires with the help of the researchers and research assistants in about 50 minutes and placed the answer sheets in a sealed box placed at the front of the classroom.

After the first assessment (baseline), the experimental groups were given psychoeducation on both mental illness and expectations about counseling for about 2 hours each while sited in the classroom using power point presentations and allowed about 30 minutes for them to ask questions.

The experimental group second assessment was done soon after the psychoeducation, a third one three months after the psychoeducation and a fourth one 10 months after the psychoeducation using the same instruments.

The control group did not receive any psychoeducation but were assessed three times; one at baseline, a second a day after baseline, and a third one three months after the baseline and the third one were done ten months after the psychoeducation.

Collection of data used researcher developed demographic questionnaire that asked the participants their age, gender, year of study, religion, marital status, and whether they had taught as untrained teachers before coming to college. Data was also collected using Expectations about Counseling Brief Form; developed by H.E.A. Tinsley in 1980 [13]. The Expectations about Counseling scale is made up of 66 items that grouped into 17 scales and measures expectations in three main areas, (a) Personal Commitment, (b) Facilitative Conditions, and Counselor Expertise that was created by Hatchet and Han.

\subsection{Data Management and Analysis}

Collected data was analyzed using SPSS version 23.0 to identify (a) trends of change of summative and factor mean scores; ((b) Analysis of Variance (ANOVA) in both groups and (c) post-hoc only in the experimental group.

Trends of summative scores were indicated with a line graph from the baseline assessment to the third (among the control group) and to the fourth among the experimental group. Analysis of Variance (ANOVA) -F-test was used to 
determine whether there were any statistically significant variation between means of the summative EAC-BF scale and its factors through the four or three assessments. Post Hoc analysis using the Least Significant Difference Method (t-test) was used in the experimental group to determine patterns of significant variation of mean scores between the four assessments.

\section{Results}

\subsection{Trends of Means of Expectations About Counseling}

\subsubsection{Trends of EAC-BF Summative Means Scores in the Control Group}

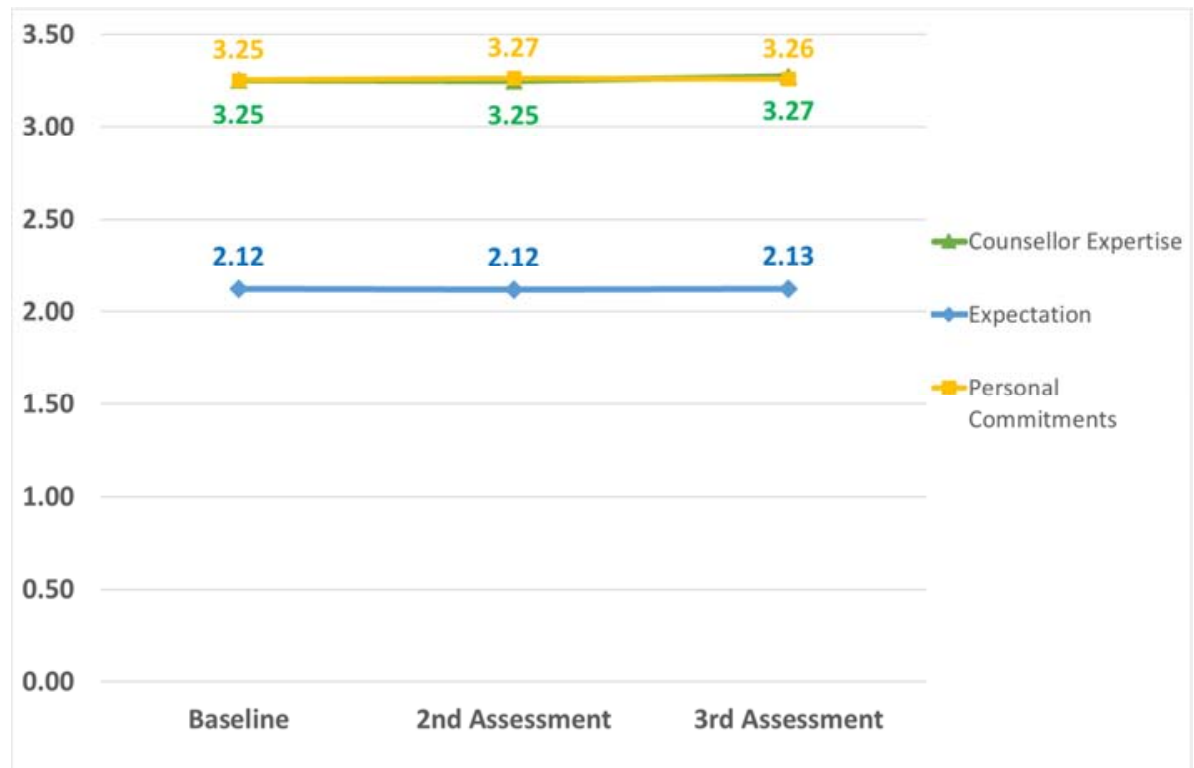

Figure 1. Trends of the mean expectations scores in the EAC-BF Factors in the Control group at the different levels of assessment.

Trends/line graphs of the means indicate a stagnant mean of expectations about counseling in both the mean scores of EAC$\mathrm{BF}$ and its factors in the control group across all the three assessments, Figure 1 above. This result indicates that there was no change in Expectations about Counseling in this group in both summative scale scores and its factors.

\subsubsection{Trends of EAC-BF Summative Mean Scores in the Experimental Group}

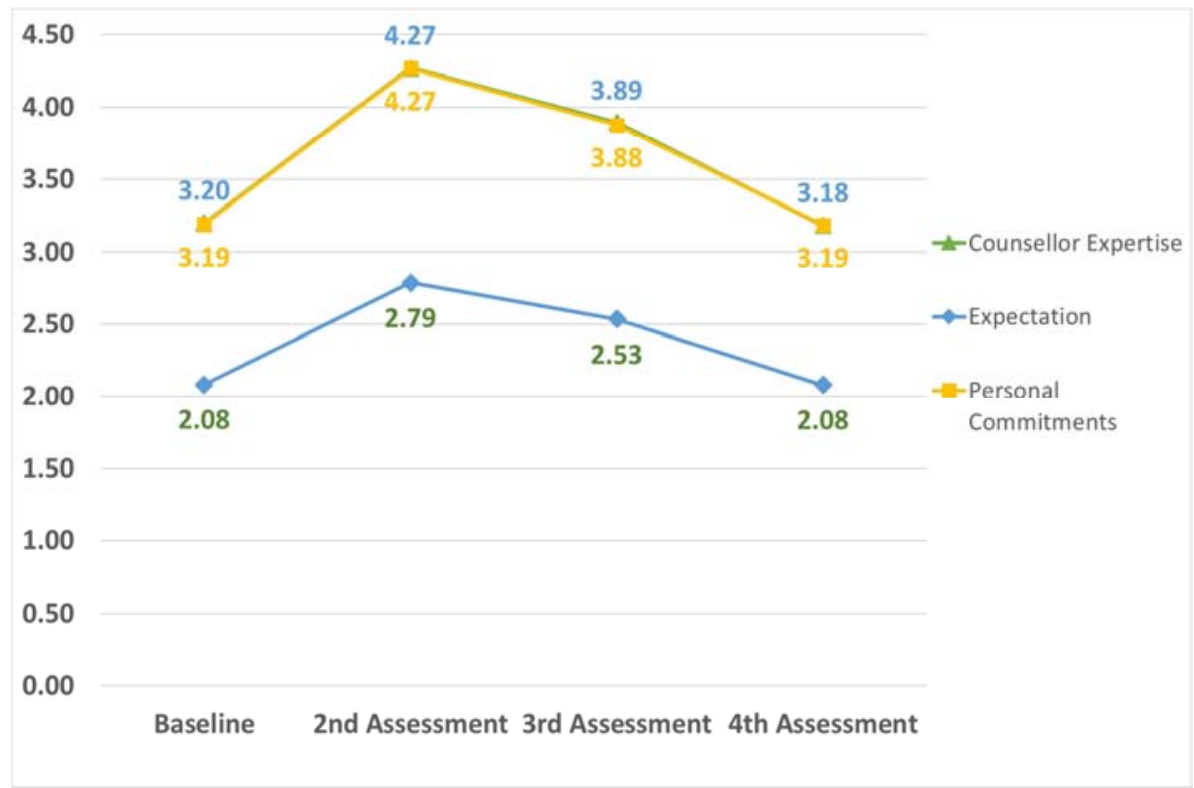

Figure 2. Trends of summative mean scores and factors of EAC-BF in expectations about counseling in the experimental group. 
The experimental group shows an increase (improvement) in the expectations about counseling and in all the factors of the EAC-BF at the second assessment immediately after psycho-education, but the improvement slowly fades away in the $3^{\text {rd }}$ and $4^{\text {th }}$ assessment and it is observed that the means go back to the same level at the baseline assessment by the time of the $4^{\text {th }}$ assessment $(10$ months after the baseline assessment), Figure 2 above.

\subsection{Significant Variations in Expectations About Counseling EAC-BF Scale Factors}

The significant variations in Expectation about counseling were determined using the ANOVA (F-test) for both the control and experimental group differently. No significant variation was indicated among the control group in the summative score and in EAC-BF factors (Table 1 below). However there was significant variation among the summative mean scores of EAC-BF and all three factors, (Table 1 below)

\subsubsection{Significant Variation of Means in the Control Group and EAC-BF Factors}

Table 1. ANOVA (F-Test) Results from the EAC-BF Scale on the Control Group

\begin{tabular}{|c|c|c|c|c|c|c|}
\hline EAC-BF Scale and Factors & & Sum of Squares & df & Mean Square & $\mathbf{F}$ & Sig. \\
\hline \multirow{3}{*}{ Expectations about Counseling Full Scale } & Between Groups & .009 & 2 & .004 & & \\
\hline & Within Groups & 139.699 & 3636 & .038 & .111 & .895 \\
\hline & Total & 139.708 & 3638 & & & \\
\hline \multirow{3}{*}{ Facilitative Conditions } & Between Groups & .127 & 2 & .064 & & \\
\hline & Within Groups & 443.226 & 3636 & .122 & .522 & .594 \\
\hline & Total & 443.353 & 3638 & & & \\
\hline \multirow[t]{2}{*}{ Personal Commitments } & Within Groups & 440.534 & 3636 & .121 & 1.243 & .289 \\
\hline & Total & 440.835 & 3638 & & & \\
\hline \multirow{3}{*}{ Counselor Expertise } & Between Groups & .059 & 2 & .030 & & \\
\hline & Within Groups & 742.040 & 3636 & .204 & .145 & .865 \\
\hline & Total & 742.099 & 3638 & & & \\
\hline
\end{tabular}

ANOVA F-Test results show no significant variation of the mean scores of the expectations and the factors from the EACBF Scale (all $p>0.05$ ), Table 1. This indicates that there was no change in summative scores of expectations about counseling and in its three factors in all the three assessments.

\subsubsection{Significant Variation in Mean Summative Scores of EAC-BF and Its Factors Among the Experimental Group}

Table 2. ANOVA (F-Test) Results from the EAC-BF Scale on the Experimental Group.

\begin{tabular}{|c|c|c|c|c|c|c|}
\hline & & Sum of Squares & df & Mean Square & $\mathbf{F}$ & Sig. \\
\hline \multirow{3}{*}{ Expectation about Counseling } & Between Groups & 495.321 & 3 & 165.107 & & \\
\hline & Within Groups & 204.101 & 5430 & .038 & 4392.590 & $.000 * *$ \\
\hline & Total & 699.422 & 5433 & & & \\
\hline \multirow[b]{2}{*}{ Facilitative Conditions } & Between Groups & 1196.937 & 3 & 398.979 & & \\
\hline & Within Groups & 689.778 & 5430 & .127 & 3140.803 & $.000 * *$ \\
\hline \multirow{3}{*}{ Personal Commitments } & Between Groups & 1199.362 & 3 & 399.787 & & \\
\hline & Within Groups & 664.120 & 5430 & .122 & 3268.754 & $.000 * *$ \\
\hline & Total & 1863.482 & 5433 & & & \\
\hline \multirow{3}{*}{ Counselor Expertise } & Between Groups & 1142.357 & 3 & 380.786 & & \\
\hline & Within Groups & 1222.199 & 5430 & .225 & 1691.759 & $.000 * *$ \\
\hline & Total & 2364.556 & 5433 & & & \\
\hline
\end{tabular}

ANOVA F-Test results show highly significant variation of the mean scores of the summative scores of EAC-BF and all the three factors from the EAC-BF Scale (all $\mathrm{p}<0.05$ ), Table 2 above

\subsection{Significant Variation of Expectations About Counseling in Assessment Stages}

A multiple comparison Post-Hoc test was conducted to find out which assessments had significantly varying means, (Table 3 below). 
Table 3. Post Hoc on Expectations about Counseling among-Experimental Group.

\begin{tabular}{|c|c|c|c|c|c|}
\hline \multirow{2}{*}{ Dependent Variables } & \multicolumn{5}{|l|}{ Comparison } \\
\hline & (I) Trial number & (J) Trial number & Mean Difference (I-J) & Std. Error & Sig. \\
\hline \multirow{6}{*}{$\begin{array}{l}\text { Expectations About } \\
\text { Counseling full Scale }\end{array}$} & \multirow{3}{*}{ Baseline } & 2nd Assessment & $-.68974^{*}$ & .00719 & $.000 * *$ \\
\hline & & 3rd Assessment & $-.44837^{*}$ & .00738 & $.000^{* *}$ \\
\hline & & 4th Assessment & .00926 & .00747 & .215 \\
\hline & \multirow{2}{*}{ 2nd Assessment } & 3rd Assessment & $.24137^{*}$ & .00745 & $.000 * *$ \\
\hline & & 4th Assessment & $.69900^{*}$ & .00753 & $.000 * *$ \\
\hline & 3rd Assessment & 4th Assessment & $.45763^{*}$ & .00771 & $.000 * *$ \\
\hline \multirow{6}{*}{ Facilitative Conditions } & \multirow{3}{*}{ Baseline } & 2nd Assessment & $-1.06756^{*}$ & .01323 & $.000 * *$ \\
\hline & & 3rd Assessment & $-.70043^{*}$ & .01357 & $.000^{* *}$ \\
\hline & & 4th Assessment & .01972 & .01373 & .151 \\
\hline & \multirow[b]{2}{*}{ 2nd Assessment } & 3rd Assessment & $.36713^{*}$ & .01369 & $.000 * *$ \\
\hline & & 4th Assessment & $1.08727^{*}$ & .01385 & $.000 * *$ \\
\hline & 3rd Assessment & 4th Assessment & $.72014^{*}$ & .01418 & $.000 * *$ \\
\hline \multirow{6}{*}{ Personal Commitments } & \multirow{3}{*}{ Baseline } & 2nd Assessment & $-1.07341^{*}$ & .01298 & $.000^{* *}$ \\
\hline & & 3rd Assessment & $-.67993^{*}$ & .01332 & $.000 * *$ \\
\hline & & 4th Assessment & .02423 & .01348 & .072 \\
\hline & \multirow{2}{*}{ 2nd Assessment } & 3rd Assessment & $.39348^{*}$ & .01343 & $.000 * *$ \\
\hline & & 4th Assessment & $1.09764^{*}$ & .01359 & $.000 * *$ \\
\hline & 3rd Assessment & 4th Assessment & $.70416^{*}$ & .01391 & $.000 * *$ \\
\hline \multirow{6}{*}{ Counselor Expertise } & \multirow{3}{*}{ Baseline } & 2nd Assessment & $-1.05177^{*}$ & .01760 & $.000 * *$ \\
\hline & & 3rd Assessment & $-.68380^{*}$ & .01806 & $.000 * *$ \\
\hline & & 4th Assessment & .00556 & .01828 & .761 \\
\hline & \multirow{2}{*}{ 2nd Assessment } & 3rd Assessment & $.36797^{*}$ & .01822 & $.000 * *$ \\
\hline & & 4th Assessment & $1.05733^{*}$ & .01844 & $.000 * *$ \\
\hline & 3rd Assessment & 4th Assessment & $.68936^{*}$ & .01888 & $.000^{* *}$ \\
\hline
\end{tabular}

Post-Hoc test results show significant $(\mathrm{p}<0.05)$ variations between the baseline and the second assessments, third assessments and not on the fourth assessment across all the three factors derived from the EAC-BF tool, (Table 3 above). This means improvement significantly was seen in the first six months but not in ten months after psychoeducation, except on the factor of Counselor Expertise.

\section{Discussion and Recommendations}

\subsection{Discussion}

\subsubsection{Trends of EAC-BF Summative Mean Scores}

The main purpose of this study was to examine whether psychoeduation improves an expectation about counseling for a mental illness among these participants in order to positively improve professional psychological help seeking behavior. Our findings suggest that a brief psychoeducation on mental illness and expectations about counseling improves expectations about counseling but for a short period, up to six months.

The experimental group that received psychoeducation improved positively in the mean scores of both summative EAC-BF and EAC-BF factors. This result is in line with findings of Gonzalez, et al [14] among college students. Psychoeducation among parents who have children that display symptoms of disruptive behavior have indicated an improved treatment outcome, [15].

Despite these results not being sustained for more than six months, increasing training in mental health and expectations about counseling in college may help disseminate same knowledge to the primary school community made up of students, parents and support staff, in the hope of improving attitudes towards seeking professional psychological help for a mental illness.

\subsubsection{Improvement and Sustainability of EAC-BF Factors After Psychoeducation}

All the three factors indicated a significant improvement $(p=0.000)$ in the three assessments, that is six months after the psychoeducation, but not in the fourth assessment, ten months after the psychoeducation. This then means that a brief psychoeducation could not be sustained more than six months to improve expectations about counseling. This finding is consistent with other findings from other research globally. Guajado \& Anderson, [16] found out that a positive change was indicated in the three EAC-BF factors when a psychoeducational intervention was provided to undergraduates.

\section{(i). Facilitative Conditions}

Those who received psychoeducational intervention demonstrated a significant variation in the three assessments, that is, up to six months $(\mathrm{p}=0.000)$ but with a decrease to nonsignificance $(\mathrm{p}=0.151)$, ten months after the psychoeducation.

\section{(ii). Personal Commitments}

Those who got the psychoeducation indicated a significant variation in the first three assessments $(\mathrm{p}=0.000)$, except in the fourth assessment. This indicates that even with a short/brief intervention, positive improvement can be seen in individuals' personal commitment to counseling. Batlink et al, [17] used 
mobile devises in psychoeducation for acceptance and commitment to therapy in daily life training for outpatients to build skills fro a variety of mental health problems. Long-term effects were demonstrated in commitment to therapy.

\section{(iii). Counselor Expertise}

Psychoeducational intervention demonstrated an improvement positively to the counselor expertise that was significant $(p=0.000)$ in the four assessments. This means that psychoeducation on expectations about counseling improves the expectations of counselor expertise even up to 10 months after the psychoeducation. This finding is a good sign in that if psychoeducation was given to college students they would most likely trust the expertize of the counselors and refer clients for counseling for a mental illness at workplace, home and the community at large. This would lead to positive attitudes towards seeking professional help from a psychological for a mental illness.

\subsection{Implications of the Study}

Positive findings that indicate that giving a brief psychoeducation to young adults on mental illness and expectations about counseling on mental illness treatment improves expectations about counseling. This improvement therefore goes a long way to also improve attitudes towards professional psychological help seeking for a mental illness. In addition, education can further be used to instill western concepts of causes and treatment of mental illness and remove traditional myths and beliefs about mental illness and the mentally ill patients.

This study however recommends that mental illness and expectation about counseling should be included in youth school or college curriculum to help them with early detection of illness and seek appropriate treatment early too.

\section{Conclusions}

This study concludes that psychoeducation on both mental illness and expectations about counseling for a mental illness, significantly positively improves expectations about counseling for a the youth. Although this improvement is not sustained for up to ten months, this program could be repeated every after six months or increase period of psychoeducation to up to a month. In addition, psychoeducation could also be included in youth training curriculum to prepare them for working with other youth in community.

\section{Acknowledgements}

Special acknowledgement is given to Dr. Muthoni Mathai for supervision of this research and Dr. Lincohn Khasakhala who assisted in the formation of the study concept. A special thanks is given to college administration for arranging modalities for data collection and psychoeducation and the participants for overwhelmingly willing to take part in this study during their busy college schedules. This study was not funded.

\section{References}

[1] Tinsley, H. E., \& Westcot, A. M. (1990). Analysis of the cognitions stimulated by the items on the Expectations About Counseling-Brief Form: An analysis of construct validity. Journal of Counseling Psychology, 37 (2), 223.

[2] Goldfarb, D. E. College Counseling Center Clients' Expectations About Counseling: How They Relate to Depression, Hopelessness, and Actual-Ideal SelfDiscrepancies, 2002; 5 (2): 142-152. DOI: 10.1002/j.21611882.2002.tb00216.x.

[3] Winograd, G. and Tryon, G. S. (2009), Counseling Expectations Among Students in an Opportunity Program: Dispositional and Cultural Influences. Journal of Counseling \& Development, 87: 438-448. Doi: 10.1002/j.15566678.2009.tb00128.x.

[4] Abreu, J. M. (2000), Counseling Expectations Among Mexican American College Students: The Role of Counselor Ethnicity. Journal of Multicultural Counseling and Development, 28: 130-143. Doi: 10.1002/j.21611912.2000.tb00341.x.

[5] Kunkel, M. A., \& Williams, C. (1991). Age and expectations about counseling: Two methodological perspectives. Journal of Counseling and Development, 70, 314-320.

[6] Kakhnovets, R. (2011), Relationships Among Personality, Expectations About Counseling, and Help-Seeking Attitudes. Journal of Counseling \& Development, 89: 11-19. Doi: 10.1002/j.1556-6678.2011.tb00056.x.

[7] Yorgason, J. B., Linville, D., \& Zitzman, B. (2008). Mental health among college students: do those who need services know about and use them?. Journal of American College Health, $57 \quad$ (2), 173-182. http://dx.doi.org/10.3200/JACH.57.2.173-182.

[8] Nyavanga, E. J. \& Barasa, M. Expectations About Counseling for a Mental Illness Among Primary School Teacher Trainees in Kenya. Science Journal of Public Health. 2016; 4 (4): 305311. doi: 10.11648/j.sjph.20160404.16.

[9] Theodora E. Katerelos, Claude Bélanger, Marie-Christine Payette, Ghassan El-Baalbaki, André Marchand and Michel Perreault (2015). The Role of Expectations in Treatment Outcome and Symptom Development in Anxiety Disorders, A Fresh Look at Anxiety Disorders, Dr. Federico Durbano (Ed.), InTech, DOI: 10.5772/60668. Available from: http://www.intechopen.com/books/a-fresh-look-at-anxietydisorders/the-role-of-expectations-in-treatment-outcome-andsymptom-development-in-anxiety-disorders

[10] Ndetei, D. M., Mutiso, V., Musyimi, C., Mokaya, A. G., Anderson, K. K., McKenzie, K., \& Musau, A. (2016). The prevalence of mental disorders among upper primary school children in Kenya. Social psychiatry and psychiatric epidemiology, 51 (1), 63-71.

[11] Ndetei, D. M., Mutiso, V., Maraj, A., Anderson, K. K., Musyimi, C., \& McKenzie, K. (2016). Stigmatizing attitudes toward mental illness among primary school children in Kenya. Social psychiatry and psychiatric epidemiology, 51 (1), 73-80. 
[12] Francis, J. M., Grosskurth, H., Changalucha, J., Kapiga, S. H., \& Weiss, H. A. (2014). Systematic review and meta-analysis: prevalence of alcohol use among young people in eastern Africa. Tropical medicine \& international health, 19 (4), 476488.

[13] Tinsley, Howard E.; Workman, Kathleen R.; Kass, Richard A. Factor analysis of the domain of client expectancies about counseling. Journal of Counseling Psychology, 1980; 27 (6): 561-570. http://dx.doi.org/10.1037/0022-0167.27.6.561

[14] Gonzalez, J. M., Tinsley, H. E., \& Kreuder, K. R. (2002). Effects of psychoeducational interventions on opinions' of mental illness, attitudes toward help seeking, and expectations about psychotherapy in college students. Journal of College Student Development, 43 (1), 51.

[15] Martinez, J. I., Lau, A. S., Chorpita, B. F., \& Weisz, J. R.
(2015). Psychoeducation as a Mediator of Treatment Approach on Parent Engagement in Child Psychotherapy for Disruptive Behavior. Journal of Clinical Child \& Adolescent Psychology, 1-15.

http://doi.org/10.1080/15374416.2015.1038826

[16] Guajardo, Jennifer M. Fende; Anderson, Timothy. An investigation of psychoeducational interventions about therapy Psychotherapy Research, Volume 17, Number 1, January 2007, pp. 120-127 (8). https://doi.org/10.1080/10503300600590637

[17] Batink T, Bakker J, Vaessen T, Kasanova Z, Collip D, van Os J, Wichers M, Germeys I, Peeters F. Acceptance and Commitment Therapy in Daily Life Training: A Feasibility Study of an mHealth Intervention. JMIR Mhealth Uhealth 2016; 4 (3): e103. DOI: 10.2196/mhealth.5437. 